\title{
Conditions for Linking School Mathematics and Moral Education: A Case Study
}

\author{
Thomas Falkenberg, University of Manitoba \\ Andrew Noyes, University of Nottingham
}

\begin{abstract}
In recent years the mathematics education research community has undergone a social turn towards a greater interest in the values and broader educational purposes of mathematics education, including issues of social justice and citizenship education. Building on these developing interests, this paper presents a conceptual framework that links the teaching of school mathematics with moral education. Then, in a case study involving two countries, England and Canada, this framework is used to explore the affordances and constraints faced by mathematics teachers in those countries if they want to intentionally practice moral education in the classroom.
\end{abstract}

\section{KEYWORDS}

Mathematics education, moral education, mathematics education in Canada, mathematics education in England, comparative education 


\section{Introduction}

The mathematics education research community has a growing interest in mathematics and society, including the importance of values (Bishop, 1999; Bishop, Seah \&Chin, 2003), broader educational purposes (D’Ambrosio, 1999; Heymann, 2003), social justice (Gutstein, 2006), and critical mathematics education (Skovsmose, 1998). These and other scholars aim to shift views on the nature of mathematics and mathematics education from it being a "depersonlized, uncontextualized, non-controversial and asocial form of knowledge” (Brown, 1996, p. 1289) towards it being a human construction and therefore "fallible" (Lerman, 1990; Ernest, 1991) or humanized (Hersh, 1997; Lakoff \& Núñez, 2000). These concerns reflect our understanding of the shifting, political nature of knowledge and of how schools will need to respond to these shifts in the future. Hoyles et al. (1999, p. 3) predicted that "mathematics education in the third millennium will not just be about teaching and learning mathematics, but about the nature of knowledge and the place of mathematics within society". Critical mathematics educators argue that one of the central aims of the school curriculum should be a concern to understand the place, purpose and power of mathematics in society. The pedagogies which result from such a position are not commonplace in classrooms so there remains considerable work to understand why this is and how it might be different. Therefore, we look again at school mathematics, which as Popkewitz (2004) points out, is not the same as academic mathematics, but is rather one of the many interfaces between mathematics and society, in order to see the obstacles and opportunities for one dimension of this social turn in school mathematics: moral education.

In acknowledging the interplay between mathematics and human experience we begin to understand how mathematics works in, and on, society. Mathematics formats (Skovsmose, 1994) our experience in the world through, for example, the gatekeeping role of school mathematics and/or the organising of our daily lives via a vast array of visible and hidden mathematical technologies (Skovsmose, 2005). Consequently, the teaching and learning of mathematics is necessarily, but rarely admittedly, tangled up with moral questions. It is important for 
mathematics educators to appreciate this role of (school) mathematics so that in turn learners can come to appreciate how mathematics works in society. If such a shift is to translate into actual educational practice in schools, it seems clear that certain political, socio-cultural and curricular conditions need to be in place (Author2, 2007). Such changes are complex and politically sensitive, and this paper seeks to make sense of some of the challenges that are faced by educators wanting to move in this direction. Whilst we acknowledge the work undertaken by critical mathematics educators, our contribution here is upon developing an understanding of the structural constraints which inhibit regular teachers' explicit engagement with moral education in mathematics classrooms. We leave the development of a fuller vision for another paper.

Although there is a social/cultural dimension to school mathematics there is a great deal of similarity in mathematics education systems around the world. International comparative studies like TIMSS (http://timss.bc.edu) and PISA (http://www.pisa.oecd.org) and the resulting efforts by governments to improve their position in what Brown (1998) calls 'the tyranny of the international horse race' have most likely contributed to such homogenizing. However, historical variation in political and educational governance leads to notable differences in classroom experiences of learning mathematics. Drawing upon our experiences of mathematics education in Canada and England, we set out to explore some of affordances and constraints facing mathematics teachers that are interested in developing a moral dimension in their teaching of mathematics.

It is clear from the policy and scholarly literature that there are different notions of moral education and different realisations of moral education in practice. So, this paper continues by presenting and developing our conceptual framework, outlining its potential for promoting engagement in intentional moral education. We then proceed to discuss, albeit briefly, two national contexts of mathematics education: England and Canada. We felt most comfortable with these two contexts because of our own situatedness, but these two cases should also be of more 
general interest as they represent different historical forms of educational governance which have impacted upon mathematics classrooms in a variety of ways.

\section{Moral Education and Mathematics School Education}

The argument for the moral purpose of schooling, and therefore of moral education, is common in education research literature (Dewey, 1975, Goodlad et al., 1990; Noddings, 1992; Hansen, 2001; Cambell, 2003) as well as in teacher practitioner literature (Lickona, 1991; Borba, 2001; DeRoche \& Williams, 2001; Gootman, 2001). Connections between mathematics education and moral education (understood in this traditional perspective), however, are rare (for some exceptions see Güting, 1980; Wicks, 1981, 1982; Heymann, 2003; Author1, 2006; Warnick \& Stemhagen, 2007). In this paper we take the more general educational notion of moral education as the starting point of our discussion, from which we develop the conceptual framework for our analysis of the contexts of teaching and learning of school mathematics in England and Canada. This approach will complement the work by a number of authors we mentioned at the beginning of the introduction, who all take more or less a different starting point than we do, but, as mentioned, do so with a similar perspective on the importance of the link between mathematics teaching and society. ${ }^{1}$

We understand moral agency in a broad sense (see below) and our thinking about moral education in school mathematics draws on a variety of perspectives. Moreover, the larger purpose of mathematics education is grounded in the moral purpose of schooling, which is

\footnotetext{
${ }^{1}$ Investigating the connections between those approaches and the one we take would be of great interest but would go beyond the limits of this paper, since the relationships seem to be quite complex. For instance, Bishop in his seminal work on values in mathematics education, e.g. Bishop, Seah and Chin (2003), conceptualizes moral values as only one type of values in teaching while we have a more comprehensive concept of morality; also, Bishop has more a
} 
primarily about helping students develop as human beings with moral agency within a particular socio-cultural and political context. Our conceptualisation of moral agency and, therefore, of moral education draws on Johnson's (1993, 1996, 1998) notion of 'moral understanding' and Dewey's (1975) 'moving ideas'.

Moral agency is centrally characterized by moral understanding, which Johnson (1993, p. 198) sees as being morally insightful and morally sensitive. The former is to capture the need to understand our functioning as human beings in general and as human agents in particular. As human agents we are able to discriminate, envision new possibilities and imaginatively explore the implications of our particular biases, judgments, convictions, and so on. We have insights into how socio-cultural and political environments affect our functioning as moral agents and can enable or constrain human and societal development and flourishing. Being morally sensitive is the ability to

put ourselves in the place of another, [to] enlarge our own perspective through an imaginative encounter with the experience of others, [to] let our own values and ideals be called into question from various points of view.

(Johnson, 1993, p. 199)

Moral education, then, has the task of developing moral understanding in learners, thus, helping them to become morally insightful and sensitive. But our moral understanding has to be grounded in a 'perspective on the world' (Gadamer, 2003). It is only on the ground of what we bring with us in terms of our biases, judgments, convictions, and so on that we are able to be morally sensitive and insightful. Dewey's (1975) notion of 'moving ideas' captures the notion transformational. 
that a moral orientation is necessary to frame our moral understanding. The idea of a (necessary) 'moral orientation' is the second central characteristic of our view of moral agency.

Following Dewey, we see the development of intellectual ideas as centrally a moral endeavour and we want students to appropriate intellectual ideas "in such a vital way that they become moving ideas, motive-forces in the guidance of conduct" $(1975$, p. 2). We want those intellectual ideas to affect students' moral agency, their moral understanding. This raises the question as to how such intellectual ideas might be usefully developed in school mathematics classrooms. Here we need to remain mindful of the fact that moral education is subject to particular socio-political and cultural conditions (Author1, 2007) so good examples of intellectual ideas might only be so in a particular context. Despite this problem of particularity we argue, along with many of the scholars cited herein, that the interrelated issues of power, (in)equality and democracy are of central importance in (moral) education, and therefore should also be important in mathematics education. For space reasons, we would like to limit our exemplification to two examples.

Warnick and Stemhagen (2007) argue that mathematics, as a technology, is not morally neutral. This idea needs to become a moving idea in the teaching of mathematics. Whether the assumption of non-neutrality is valid for the most esoteric pure mathematics (as in Hardy's famous claim) is a moot point but for our discussion of school mathematics, where curriculum is intentionally utilitarian, the argument holds. Engaging with mathematics, Warnick and Stemhagen (2007, p. 306) argue, means modeling reality through simulation. Mathematics is then inherently non-neutral because "such representations must leave out certain aspects of what is being represented. Indeed, this 'leaving-out' is precisely what makes the simulation useful." (Warnick and Stemhagen, p. 306). Skovsmose (2005) extends this point in his discussion of economic and political forecasting models in Denmark asking questions around who gets to set the model's assumptions and parameters and whose interests get served (and overlooked) in such decisions. The choice of what is left out in considering a mathematical simulation of reality is a 
moral choice. For instance, when teachers only set problems that have just one right answer or problems that leave non-quantifiable aspects of the larger context unconsidered students become familiar with (supposedly amoral) mathematical moving ideas. In such cases the teacher's control over what counts as mathematical activity diminishes the potential for developing moral education in the mathematics classroom. On the other hand, mathematical tasks which leave room for choice of approach and lead to different solutions to complex problems can easily introduce moral perspectives.

Warnick and Sternhagen (2007, pp. 311-312) highlight the limitations of purely quantitative approaches to problem solving; another moving idea of mathematics which we would embrace in the interest of moral education. Coming at the same issue from another direction, Gutstein (2006) argues that the quantitative power of mathematics can provide tools to uncover social injustice by quantitatively analysing real-life situations. This is an example of where a mathematical idea can be transformed into a moving idea through particular pedagogic approaches to teaching mathematics. For Gutstein, in turn inspired by Paolo Friere, this is about developing the disposition towards 'reading and writing the world with mathematics'. For instance, comparing cost and size of houses owned by different racial groups (Gutstein 2006, p. 44) allows students to use quantitative tools to explore the gentrification process impacting their urban community and thereby critique their social reality. This and other projects described by Gutstein are examples of how teachers have helped students to develop the idea of using quantitative tools to 'read one's world'. If this idea guides students in their way of engaging with the world around them it has become a 'moving idea' in Dewey's sense.

\section{Analysing the Conditions and Possibilities for Moral Education in Mathematical School}

\section{Education}

Having explored the notion of moral education and placed it in the context of mathematics education, we now describe the teaching contexts in which the ideas that we are exploring might 
be developed. ${ }^{2}$ These two sections are necessarily brief and lead into a short discussion of the future possibilities for moral education. Due to the different nature of the contexts, and the authors' current and historical locations within them, we have written these in slightly different ways. We have deliberately not contrived to smooth over these distinctions because they serve to highlight substantive differences in the trajectories of policy and practice in the two locations over time. We want to present the differences as they have enabled us to identify the taken-forgranted in our own contexts, and thereby the affordances and constraints facing mathematics educators in each country. Of course there is great variety within each of these two countries, but we will outline the commonly found traditions and dominant policies which help to shape typical encounters in mathematics education.

\subsection{England}

Unlike the Canadian provincial education system, England (in common with Wales) has had a National Curriculum (NC) since the late 1980s. The centralisation of the education curriculum and the standardised national assessment of progress against this curriculum that has grown since the early 1990s has had a major impact on the ways in which mathematics education in England has been developed in recent years. So, whereas the NC mandated curriculum content for all school learners, the National Numeracy Strategy (in primary schools) and Framework for Teaching Mathematics (influential in secondary schools since 2000) moved beyond framing curriculum to include clear directions for pedagogic practice. These two documents brought a

\footnotetext{
${ }^{2}$ To our knowledge there are no studies that would empirically support more generalized assumptions about 'teachers in Canada' or 'classroom practices in England' as they are relevant to our investigation. Nevertheless, in the following case studies we felt comfortable enough to make generalized claims about particular aspects of teaching in England and Canada based on our own experiences with and our observations of the respective schooling contexts. The reader should keep this qualifications in mind.
} 
range of new pedagogic tools into many classrooms: counting sticks, number fans, mini whiteboards, etc. In addition, a strongly framed three-part lesson format became commonplace, comprising a 10 minute starter activity, a main activity and a concluding plenary. Such a structure was not mandated but was adopted unquestioningly by most teachers. The gradual deprofessionalisation of teachers work, exacerbated by the managerialism of a national inspection sytem and the performative imperetive of school league tables, makes it too risky for many teachers to question such 'guidance'. The formulaic way in which teachers implemented the 'three part lesson' had the effect of creating a rather monotone teaching palette in many schools and this still exists to a degree. So there was greater consistency but an often uninspiring predicatability. These new approaches brought with them a set of discourses which have been quickly adopted by teachers but have had little effect on the underlying culture of many mathematics classrooms.

Mathematics is part of the core curriculum, along with science and English. Despite repeated efforts to improve the curriculum it remains intentionally constraining on both curriculum content and pedagogy. Only now, twenty years after the initial introduction, has the Qualifications and Curriculum Authority (QCA) made a significant move towards a potentially more flexible curriculum, both within and between subjects, for learners in the early years of secondary school.

The original mathematics NC was finely detailed and hierarchically structured: 14 strands, each divided into 10 levels of attainment. The 14 strands were later consolidated into five broad content areas: using and applying mathematics, number, algebra, shape, space and measures and data handling. Shortly after the introduction of the NC a programme of national tests was established for children at the end of each Key Stage of schooling (ages 7, 11, 14, 16). The last assessment point in this series is the General Certificate of Secondary Education (GCSE) and although this is, in theory, a test of progress against the $\mathrm{NC}$ attainment targets the reality is that GCSE Mathematics is the critical entry qualification or gatekeeper to future educational and 
work opportunities. Only about half of all students reach the required grade $\mathrm{C}$ standard at the first attempt. Getting a grade C is therefore critical for the students' futures and the schools' performance and teaching to the test results in the squeezing out much of the broader curriculum aims (point 2 below).

The NC has two key principles:

- The school curriculum should aim to provide opportunities for all pupils to learn and to achieve

- The school curriculum should aim to promote pupils' spiritual, moral, social and cultural development and prepare all pupils for the opportunities, responsibilities and experiences of adult life.

So the NC for England and Wales includes an explicit reference to young people's moral education. However, it is not all that clear what this moral education is and given that there are various ways of understanding moral education we might expect further clarification. There is a small amount of further 'guidance' in the mathematics NC document:

- moral development, helping pupils recognise how logical reasoning can be used to consider the consequences of particular decisions and choices and helping them learn the value of mathematical truth

There is an interesting assumption made here, namely that mathematics education can actually provide pupils with logical reasoning skills, which then in turn can be used in the moral domain of those pupils' lives. There is also the assumption that moral engagement ('moral understanding' or 'moral acting') involves logical reasoning in an important way. Why should logical reasoning used in a mathematical context transfer to a moral domain context? Moral understanding involves understanding situations and people and because mathematical logical reasoning is far simpler and 'cleaner' than what people encounter in moral situations the link is not so clear. There is certainly no clear notion of the moving ideas referred to earlier or of 
seeing mathematics as value-laden and non-neutral. Rather mathematical 'truth' is brought to bear on moral thinking and action but the two domains remain mutually exclusive.

Suffice to say, despite the mathematics NC's lip service to spiritual, moral, social and cultural development, mathematics teachers in the UK have not been very successful in achieveing these curricular goals. The NC advice on moral development is unhelpful and there is little more support for teachers in this regard. Relating to the aims of the NC aims Gill (2004, p. 115) asserts that

the current curriculum for mathematics fails to meet the claims made for it in mathematical terms and also fails to contribute to the overall ethos of the National Curriculum contained in the Aims and Values. Nothing less than a complete overhaul is necessary if it is to serve our pupils and the society they, and we, live in.

In England there is an enduring, and even increasing, emphasis on mathematics as utility and in the light of ongoing twin-pronged national concerns about a) the supply of mathematics- and mathematics-related - graduates and b) the mathematical competence of the workforce in general, the curriculum from 2010 (especially the revised 14-19 curriculum) will include what is intrigueingly called functional mathematics. Such utilitarian perspectives envisage school mathematics as a set of tools and this metaphor includes an implication of neutrality, since those tools are conceptulized solely as means without considering the (moral) ends of their use as a technology (see above). However, perhaps this might be a critical moment at which to develop learner understandings of mathematics as a technology, i.e. tools in use for a purpose, which has implicit moral assumptions, as discussed above. But functional mathematics is not being introduced to prepare critical citizens who appreciate the moral dimensions of mathematical applications. Rather, the aim is more one of formatting (Skovsmose 1998), of training the future 
workforce with the skills that our politicians tell us we need to guarantee future economic prosperity.

In recent years there has been growing concern about the school curriculum in the UK; its overly prescriptive nature and level of relevance for the 21 st Century. So the curriculum in the UK is undergoing dramatic changes - at least in theory. Following the influental government reports chaired by Tomlinson (DfES, 2004) and Smith (2004), mathematics in the 14-19 age range is being overhauled in the next few years; although where it will end up remains unclear. Meanwhile, at lower secondary level there is a new curriculum that has a greater emphasis on processes. A closer reading of these apparently progressive curriculum documents does not reveal developed understanding of the social, cultural or moral in mathematics education:

Mathematical thinking is important for all members of a modern society as a habit of mind for its use in the workplace, business and finance; and for personal decision-making. Mathematics is fundamental to national prosperity in providing tools for understanding science, engineering, technology and economics. It is essential in public decision-making and for participation in the knowledge economy.

Mathematics equips pupils with uniquely powerful ways to describe, analyse and change the world. It can stimulate moments of pleasure and wonder for all pupils when they solve a problem for the first time, discover a more elegant solution, or notice hidden connections. Pupils who are functional in mathematics and financially capable are able to think independently in applied and abstract ways, and can reason, solve problems and assess risk.

(QCA, 2007, p. 139) 
There seems to be room here for developing moral agency, 'personal decision making' must surely involve moral consideration and if one is seeking to 'change the world' (i.e. using mathematics as a technology) this too must have moral implications. However, whether and how this gets translated into classroom experiences is an important question and one that has been discussed in the UK context (Winter, 2001; Author2, 2007).

One enduring feature of school mathematics in England during these last twenty years of curriculum development is the powerful role of assessment in shaping classroom practices: the adage 'what you test is what you get' is quite true here. Teachers at all levels have become adept at preparing young people to sit national examinations that not only impact upon learner trajectories but, through the publication of school league tables, impact upon school trajectories and teachers' performance management processes. So what is testable becomes of central importance to all: learners, teachers, schools, parents and government. This general surveillance of the school system and marketisation of school choice becomes even greater through the use of school effectiveness measures that apparently show which schools are most likely to add the most value to parental investment (i.e. their children). In this culture examination success becomes paramount and teachers and learners become instrumental: outcomes count, processes do not; marks speak, moral considerations are obscured. So mathematics education has become a victim of what Ball calls "the terrors of performativity" (Ball, 2003). If there is one chink of light in all of this it is a growing discontentment amongst teachers about this performative mode. This is leading some to ask those bigger questions about the purpose of the curriculum but asking the question is not sufficient to escape the pressure of the league table. Moreover, we now have a generation of teachers who have not only taught in this culture throughout their career but have also been schooled into performativity as students. One potential for change is the current move to develop teaching as a Masters level profession which a plethora of masters courses for teachers springing up. Perhaps this intellectual space (if it can be wrestled from the 
grip of performativity) can help teachers to examine their values critically in a way which might lead to shifts in practice. Time will tell.

It is easy to see how such an overemphasis on assessment - and children in England are considered to be amongst the most heavily tested in the world - can have limiting effect on the potential for the moral, social, cultural in mathematics lessons to flourish. However, even if such a dominant testing regime were to be instantly abolished the culture that it has helped to create would probably remain strongly imprinted upon classrooms. Indeed, those of us who were educated in England before the introduction of the NC do not hark back to the golden age of mathematics education for social justice and moral engagement. Much of the curricular experience of today is similar to that of the previous generation. Ability grouping for mathematics remains almost universally accepted (in England) and supported by the bewildering array of text-books, many of which are tied to examination courses and authored by test writers.

The underlying problem is that school mathematics in England has been largely utilitarian for a long time now and despite the efforts of a minority of teachers and scholars, who maintain a vision for mathematics education that might offer the opportunity for learners to develop moral reasoning in relation to mathematics, their voice is a relatively quiet one. Moreover, the deeply entrenched cultural view of mathematics education in England is not something that can be changed overnight (Author2, 2004). Indeed, perhaps a better line of attack on this problem might be to develop the notion of utility, or mathematics as technology, as a useful moving idea through which to develop new ways of thinking about mathematics teaching and learning. Professional development needs to go beyond the very important 'how to' and aim to develop new understandings of what mathematics education is for if we are to develop moral education. The problem here is that 'how to' is often motivated by raising attainment in a competitive climate. Here the formatting power of mathematics (or rather statistics), works on the learners and their teachers. 


\subsection{Canada}

To investigate the conditions (possibilities and constraints) for moral education through the teaching of mathematics in Canada we will consider the schooling context in general and the curricular context in particular. Enacting moral education through the teaching of mathematics appears reasonably possible within the general schooling and curricular context for teachers in the Canadian school system, although the development of students' moral agency and the addressing of the suggested moving ideas are not explicitly conceptualized as part of mathematics education in any of the contexts here considered. So, let us firstly consider the schooling context.

Canada has ten provinces and three territories. Formal education at all levels, primary to tertiary, falls under provincial and territorial jurisdiction, respectively. ${ }^{3}$ School curricula are mandated at the provincial or territorial level, though schooling is administered and teachers are hired locally at the level of school divisions. The responsibility for monitoring the implementation of the provincially mandated curriculum lies with the school divisions with the exception of province / territory-wide mandated and ministry-designed summative examinations.

Although schooling is administered at the local school-board level, it is provincial school acts that legally frame this administration. There are some school acts that articulate a general purpose of the school system, while others solely deal with administrative matters. An example for the former is the school act of the province of Manitoba. In it the provincial government lays out the role and the purposes of the education system:

A strong public school system is a fundamental element of a democratic society

... the purpose of the public school system is to serve the best educational 
interests of students ... the public school system should contribute to the development of students' talents and abilities ... public schools should contribute to the development of a fair, compassionate, healthy and prosperous society

(Manitoba Ministry of Education, Youth and Citizenship, n.d.)

Notions of moral education of the type suggested here are central to schooling in Canada and although the development of moral understanding and sensitivity as part of the teaching of mathematics is not found explicitly written into curriculum (cf. Mathematics NC in England), neither are they excluded by Canadian school acts.

As in England, we know that external examinations have an impact on what and how teachers teach. In Canadian schools, in particular at the high school level, teachers and students encounter provincial and school-based, cross-grade summative examinations. Most provinces use provincially designed and administered standard tests for their mathematics courses in the graduate year (grade 12). These final exams contribute a particular percentage to the final grade for students in the respective mathematics course. Sometimes, such final exams are designed and administered at the school division level. In particular the high-stakes external tests at the grade 12 level can impact on mathematics teachers' willingness to spend time on the development of students' moral understanding. However, with little external testing taking place in Canada (mainly at the grade 12 level), moral education in the teaching of mathematics can be given serious consideration.

In addition to mandated curricula some provincial ministries provide suggested educational material or ideas for classroom teaching practice. We want to briefly discuss two examples that

\footnotetext{
${ }^{3}$ The education of Aboriginal students on reserves, however, falls under the jurisdiction of the federal government. Because of the more general purpose of our paper, we will not discuss this special situation.
} 
are relevant for the purpose of this paper to illustrate how two provincial educational authorities promote moral education in a wider sense in schools.

The first example is the Social Responsibility Performance Standards (British Columbia Ministry of Education, 2001), which are offered for voluntary implementation for grades K-10 in British Columbia. The document provides teachers with a rubric to assess their students in four areas: contributing to the classroom and school community, solving problems in peaceful ways, valuing diversity and defending human rights, exercising democratic rights and responsibilities. The second example is Ontario's “character development initiative” (http://www.edu.gov.on.ca/ eng/literacynumeracy/character.html). ${ }^{4}$

Both initiatives suggest an explicit interest by the respective provincial governments in moral education or moral development. However, neither initiative is explicitly suggested as being integrated into the teaching of mathematics. Furthermore, the purpose of moral education / development is in both examples quite different from what we have suggested in the previous section. Although it can be well argued that the aspects of human performance assessed in the Performance Standards for Social Responsibility are grounded in central aspects of the moving ideas we suggested in the previous section, British Columbia's initiative is only concerned with the assessment of the degree to which those ideas are indeed guiding students' conduct, but not with the development of those ideas as moving ideas in students. Also, the performance assessment is very much grounded in a behaviouristic framework and, thus, is less concerned with 'moral understanding' as we understand it.

The focus of the Ontario initiative is on "safe and orderly learning environment", and character education is here understood as having students socialize through adaptation into the already established order and structure of a given school culture. Also, the notion of "character

\footnotetext{
${ }^{4}$ The current premier of the province of Ontario has explicitly committed the Ontario school system to ‘character education' (McGuinty, 2003).
} 
development" in the Ontario initiative is uncommonly broad if "improved employability skills" and "improved academic achievement" are considered to fall under character development.

Nevertheless, both governmental initiatives suggest that in the Canadian school context moral education is within the intended realm of public education, at least in some educational jurisdictions. The goals of "improved interpersonal relationships, "improved life preparation", and "positive school culture" in the Ontario initiative can even be directly connected to the moral moving ideas and the moral understanding we described in the previous section if those goals are interpreted as going beyond socializing students to function well in the already established social structure.

Having considered the schooling context we now focus on curricula, which, in Canada are written and mandated at the provincial level, though the implementation responsibility lies with the local school divisions. Because the learning objectives of the curricula are mandated, they have the biggest impact on the content of the teaching of mathematics in Canada.

In December 1993 the four western provinces of Canada and the two territories signed The Western Canadian Protocol for Collaboration in Basic Education: Kindergarten to Grade 12 $(\text { later } W N C P)^{5}$. The main purpose of the $\mathrm{WNCP}$ is to provide a negotiated common $\mathrm{K}-12$ curriculum framework for the signatories to the Protocol (see www.wncp.ca). Currently, there are curriculum frameworks in place for English language arts, international languages, mathematics, and social studies. The Protocol allows each signatory to implement the commonly negotiated frameworks in the way they see fit. A recent survey among the Protocol signatories established for the then current K- 12 WNCP Mathematics Framework a self-declared 80-100\% rate of implementation (McAskill et al., 2004, p. 119), with the exception of grades 8 and 9, which had a self-declared implementation range of about $67-92 \%$.

\footnotetext{
${ }^{5}$ The Western Canadian Protocol for Collaboration in Basic Education Kindergarten to Grade 13 was renamed to the Western and Northern Canadian Protocol for Basic Education (WNCP) when Nunavut joined the Protocol.
} 
Of particular interest here is the introduction section of the Curriculum Framework for Mathematics in which the goals and the conceptual framework for the learning of mathematics as well as assumptions about students as learners of mathematics are articulated. The Framework describes one of the "critical components that students must encounter in a mathematics program in order to achieve the goals of mathematics education and encourage lifelong learning in mathematics" (WNCP, 2006, p. 6) as follows:

Students are expected to: . . . connect mathematical ideas to other concepts in mathematics, to everyday experiences and to other disciplines .... When mathematical ideas are connected to each other or to real-world phenomena, students can begin to view mathematics as useful, relevant and integrated. (WNCP, 2006, pp. 6-7)

Such real-world connections are often limited to pseudo realistic calculations, for example the fuel consumption on a vacation trip or to calculating the trajectory of a basketball thrown by a student in a game. Beyond that, the "critical component" of connecting mathematical ideas to genuine everyday experiences or scientific and social issues allows us to introduce and develop moving ideas that students can engage with in order to development their moral understanding and sensitivity.

In sum, neither Canadian school policy nor curricula explicitly link mathematics education with moral education but there does exist a space of potential for developing moral understanding and moving ideas in the teaching of mathematics. The relative professional autonomy in instructional decision making enjoyed by Canadian classroom teachers provides a supportive condition for integrating moral education into the teaching and learning of school mathematics in Canada. However, this condition is not sufficient for ensuring a widespread move towards developing moral education in mathematics classrooms. 


\section{Discussion}

The first substantive point we want to make is that moral education is not designed into the mathematics curriculum in either country, and where it is mentioned the sense is quite different from that developed in this paper. As a result, if mathematics educators want to take this discussion forward then the development of a shared understanding of terms is important, and our paper contributes to developing such a shared understanding. As we outlined earlier, the moral purpose of schooling is to help students with the development of their moral agency by helping them develop moving ideas and moral understanding and sensitivity. Developing a moral orientation through moving ideas goes together with helping students develop their moral understanding in the sense explicated by Johnson. Before considering the potential for progress we want to re-examine the NC example of moral education as it raises a number of points regarding what moral education is, and is not.

In the NC for England and Wales, mathematics is presented as a tool for thinking about moral issues which then contributes to students' moral development. This connection between mathematics education and students' moral development is problematic in two respects. Firstly, the articulated connection in the mathematics curriculum seems very artificial and uncommitted and is without reference as to how such linking is possible. The second problematic aspect of this perspective on moral education is the two assumptions framing this link. The first assumption is that logical reasoning in the realm of 'doing mathematics' can be directly transferred to the realm of thinking about the (moral) consequences of one's decisions. There is strong evidence that transfer from one experiential domain to another does generally not happen easily (Gick and Holyoak 1980; Detterman 1993). Since Thorndike's (1924) investigations on the transferability of learning practices there can be much doubt about any straightforward transfer of more general skills (reasoning logically) from one human experiential domain (doing 
mathematics) to another (thinking about the consequences of one's decision). Where arguments and evidence are presented for transferability of general thinking skills across subject matter domains, the suggestions for how to proceed point to the great complexity of the teaching design required to achieve transferability, a complexity that goes for beyond what the NC envisions for mathematics teaching (for an example of the complexity involved in teaching of critical thinking skills for transfer across domains see Halpern, 1998). The second assumption made is that the type of reasoning exemplified and practiced in the learning of mathematics is of relevance to reasoning in the moral domain. Damasio (1994) has documented how human decision making in the social domain is centrally guided by our emotions. The assumptions to be made in decisions in the social domain are so complex and, thus, uncertain, that any level of certainty in logical derived 'consequences' of our decision are misplaced. We do not doubt that logical reasoning plays a role in moral deliberation. However, we question any claim of certainty or 'truth' in using logical reasoning to consider the (moral) consequences of one's decisions. Rather, we have argued that in bringing mathematics into moral education, questions about the use of mathematical tools can draw moral judgements into the domain of school mathematics, rather than vice versa.

The second issue we want to discuss is the increased impact of assessment on mathematics learning and the potential for moral education. We know that assessment regimes constrain lesson content and pedagogy so where there is a greater amount of testing there is less space for curricular innovation and opportunity for spending time on teaching which cannot be tested such as moral development. The scale of testing is considerably less in the Canadian schooling context than in the English context. That said, although comprehensive testing regimes like those in England might inhibit the development of moral education they have not in any sense pushed moral education out of the mathematics classroom, for it was probably not very common beforehand. When there was greater professional autonomy it was not used to develop mathematics education, although such regimes may now act as a barrier to progress in that 
direction. Or, perhaps these sustained performative pressures could lead to teachers questioning and resisting these market influences in ways that lead to the development of new forms of pedagogy, including moral education.

Our third substantive point concerns how different levels of professional autonomy and curriculum frameworks both limit and open spaces for development. In the Canadian schooling context there is no explicit reference to moral development of schooling. Nevertheless, as argued above, there is potential in Canada to link the teaching of mathematics with moral education. Canadian teachers have almost complete pedagogic freedom to accomplish curriculum learning outcomes, although such freedom does not imply the will to develop moral education. To what extent is autonomy in pedagogical matters a precondition for any implementation of moral education in the teaching of mathematics? In contrast to Canada, mathematics teachers in England have for some years been strongly encouraged to adopt particular pedagogic practices. We also believe that the localization of educational decisions in Canada compared to the nationalization of educational decision making in the English context are a central contributing factor in this greater professional autonomy in Canada compared to England, affording Canadian teachers more space to integrate broader issues such as moral education into the curriculum.

In England, one of the major policy drives is towards developing greater functional skills and realistic applications in mathematics, which incorporates mathematical modelling and problem solving. This policy is predicated upon the view that England's future economic prosperity is dependent upon a mathematically skilled workforce. This policy might also provide an opportunity for teachers and academics to contend for greater connection between mathematics and moral education.

There is one characteristic that both countries have in common: a general commitment of the schooling authorities to the moral development of students. However, in both cases, as discussed in the case studies, the commitment is more at the suggestive level than at the specific curricular level. In section 2 we have discussed - with reference particularly to Warnick and Stemhagen 
(2007) - that as a technology mathematics is never morally neutral, and that mathematics teachers engage in moral education by default, just generally not in an explicit and intentional way. With schooling authorities generally being committed to students' moral development and mathematics teaching providing the room for moral education, why have mathematics teachers not picked up on these opportunities to influence students' moral development intentionally and explicitly? There are most likely several factors, but one we are certain of is a widespread belief among mathematics teachers in what Lakoff \& Núñez (2000) call "the romance of mathematics". Belief in mathematics as amoral, objective, absolute, 'black and white', etc., makes it hard for teachers to conceptualize mathematics education contributing to students' moral development. This has - from our view of the moral purpose of schooling - an important implication for mathematics teacher education: mathematics student teachers need to be helped to develop an understanding of mathematics as a human endeavour that allows addressing aspects of social problems and the human aspects of doing mathematics.

\section{References}

Author1 (2006) [details removed for peer review]

Author1 (2007) [details removed for peer review]

Author2 (2004) [details removed for peer review]

Author2 (2007) [details removed for peer review]

Ball, Stephen (2003). The teacher's soul and the terrors of performativity. Journal of Education Policy, 18(2), 215-228.

Bishop, A. J. (1999). Mathematics teaching and values education - An intersection in need of research. Zentralblatt für Didaktik der Mathematik / International Reviews on Mathematics Education, 31 (1), 1-4. 
Bishop, A. J., Seah, W. T., \& Chin, C. (2003). Values in mathematics teaching - The hidden persuaders? In A. J. Bishop et al. (Eds.), Second international handbook of mathematics education (pp. 717-766). Dordrecht: Kluwer.

Borba, M. (2001). Building moral intelligence: The seven essential virtues that teach kids to do the right thing. San Francisco, CA: Jossey-Bass.

British Columbia Ministry of Education (2001). Social responsibility: A framework. Victoria, BC: Author. Retrieved June 1, 2007, from http://www.bced.gov.bc.ca/perf_stands/social_resp.htm)

Brown, M. (1998). The tyranny of the international horse race. In R. Slee, G. Weiner \& S. Tomlinson (Eds.), School effectiveness for whom? Challenges to the school effectiveness and school improvement movements (pp. 33-47). London: Falmer Press.

Brown, S. I. (1996). Towards humanistic mathematics. In A. J. Bishop (Ed.), International handbook of mathematics education (pp. 1289-1321). Dordrecht: Kluwer.

Campbell, E. (2003). The ethical teacher. Maidenhead, England: Open University Press.

Damasio, A. R. (1994). Descartes' error: Emotion, reason, and the human brain. New York: Putnam.

D’Ambrosio, U. (1999). Literacy, matheracy, and technoracy: A trivium for today. Mathematical Thinking and Learning, 1(2), 131-153.

DeRoche, E., \& Williams, M. M. (2001). Educating hearts and minds: A comprehensive character education framework ( $2^{\text {nd }}$ ed.). Thousand Oaks, CA: Corwin Press.

Detterman, D. K. (1993). The Case for the prosecution: Transfer as an epiphenomenon. In D. K. Detterman \& R. J. Sternberg (Eds.), Transfer on trial: Intelligence, cognition, and instruction (pp. 1-24). Norwood, NJ: Ablex.

Dewey, J. (1975). Moral principles in education. Carbondale, IL: Southern Illinois University Press. (First published 1909) 
DfES (2004). Final report of the Working Group on 14-19 Reform. London: Department for Education and Skills

Ernest, P. (1991). The philosophy of mathematics education. Basingstoke, England: Falmer Press.

Gadamer, H.-G. (2003). Truth and method (2 $2^{\text {nd }}$ ed.). New York: Continuum.

Gill, P. (2004). Mathematics. In J. White (Ed.), Rethinking the school curriculum: Values, aims and purposes (pp. 104-116). London: RoutlegeFalmer.

Gick, M. L., \& Holyoak, K. J. (1980). Analogical problem solving. Cognitive Psychology 12, 306-355.

Goodlad, J. I., Soder, R., \& Sirotnik, K. A. (Eds.).(1990). The moral dimensions of teaching. San Francisco: Jossey-Bass.

Gootman, M. E. (2001). The caring teacher's guide to discipline: Helping young students learn self-control, responsibility, and respect ( $2^{\text {nd }}$ ed.) Thousand Oaks, CA: Corwin Press.

Güting, R. (1980). Humanizing the teaching of mathematics. International Journal of Mathematical Education in Science and Technology, 11(3), 415-425.

Gustein, E. (2006). Reading and writing the world with mathematics: Toward a pedagogy for social justice. New York: Routledge.

Halpern, D. F. (1998). Teaching critical thinking for transfer across domains: Dispositions, skills, structure training and metacognitive monitoring. American Psychologist, 53(4), 449455.

Hansen, D. T (2001). Teaching as a moral activity.” In V. Richardson (Ed.), Handbook of Research on Teaching ( $4^{\text {th }}$ ed; pp. 826-857). Washington, DC: American Educational Research Association.

Hersh, R. (1997). What is mathematics, really? New York: Oxford University Press.

Heymann, H. W. (2003). Why teach mathematics? A focus on general education. Dordrecht: Kluwer. 
Hill, T. E. Jr. (2001). Autonomy of moral agents. In L. C. Becker \& C. B. Becker (Eds.), Encyclopedia of ethics (3 vols., $2^{\text {nd }}$ ed., pp. 111-115). New York: Routledge.

Hoyles, C., Morgan, C., \& Woodhouse, G. (1999). Introduction. In C. Hoyles, C. Morgan, \& G. Woodhouse (Eds.), Rethinking the mathematics curriculum (pp. 1-3). London: Falmer Press.

Johnson, M. (1993). Moral imagination: Implications of cognitive science for ethics. Chicago: The University of Chicago Press.

Johnson, M. (1996). How moral psychology changes moral theory. In L. May, M. Friedman, \& A. Clark (Eds.), Mind and morals: Essays on cognitive science and ethics (pp. 45-68). Cambridge, MA: MIT Press.

Johnson, M. (1998). Ethics. In W. Bechtel and G. Graham (Eds.), A companion to cognitive science (pp. 691-701). Malden, MA: Blackwell.

Lakoff, G., \& Núñez, Rafael E. (2000). Where mathematics comes from: How the embodied mind brings mathematics into being. New York: Basic Books.

Lerman, S. (1990). Alternative perspectives of the nature of mathematics and their influence on the teaching of mathematics. British Educational Research Journal, 16(1), 53-61.

Lickona, T. (1991). Educating for character: How our schools can teach respect and responsibility. New York: Bantam Books.

Manitoba Ministry of Education, Youth and Citizenship (n.d.). School act. Retrieved June 1, 2007, from http://web2.gov.mb.ca/laws/statutes/ccsm/p250e.php

McAskill, B., Holmes, G., Francis-Pelton, L., \& Watt, W. (2004). WNCP mathematics research project: Final report. Hold Fast Consultants. Retrieved June 1, 2007, from http://www.wncp.ca/math/Final_Report.pdf

McGuinty, D. (2003). Character education: A key part of the Ontario Liberal plan. Orbit, 33(2), 15. 
Noddings, N. (1992). The challenge to care in schools: An alternative approach to education. New York: Teachers College Press.

Popkewitz, T. (2004). School subjects, the politics of knowledge, and the projects of intellectuals in change. In P. Valero and R. Zevenbergen (Eds.), Researching the socio-political dimensions of mathematics education (pp. 251-268). Dordrecht: Kluwer Academic Publishers.

QCA (2007). Mathematics programme of study: Key stage 3. London: Author.

Smith, A. (2004). Making mathematics counts. London: HMSO.

Skovsmose, O. (1994). Towards a philosophy of critical mathematics education. Dordrecht: Kluwer.

Skovsmose, O. (1998). Linking mathematics education and democracy: Citizenship, mathematical archeology, mathemacy and deliberative interaction. Zentralblatt für Didaktik der Mathematik / International Reviews on Mathematics Education, 30(6), 195203.

Skovsmose, O. (2005) Travelling through Education: uncertainty, mathematics, responsibility. Rotterdam. Sense Publishers

Taylor, C. (1985). The concept of a person. In Charles Taylor, Philosophical papers 1: Human agency and language (pp. 97-114). Cambridge: Cambridge University Press.

Thorndike, E. L. (1924). Mental discipline in high school studies. Journal of Educational Psychology 15, 1-22.

Warnick, B. R., \& Stemhagen, K. (2007). Mathematics teachers as moral educators: The implications of conceiving of mathematics as a technology. Journal of Curriculum Studies, 39(3), 303-316.

Western and Northern Canadian Protocol [WNCP] (2006). Common curriculum framework for K-9 mathematics. Retrieved June 1, 2007, from http://www.wncp.ca/math/ccfkto9.pdf 
Wicks, R. S. (1981). Morality and the schools (Occasional Paper 32). Washington, DC: Council for Basic Education.

Wicks, R. S. (1982). Moral education: The responsibility that teachers can't avoid. Curriculum Review, 21(1), 20-24.

Winter, J. (2001). Personal, spiritual, moral, social and cultural issues in teaching mathematics. In P. Gates (Ed.), Issues in mathematics teaching (pp. 197-214). London:

RoutledgeFalmer. 